\title{
Erratum to: Overview of SIMS-Based Experimental Studies of Tracer Diffusion in Solids and Application to $\mathrm{Mg}$ Self-Diffusion
}

Nagraj S. Kulkarni, Robert J. Bruce Warmack, Bala Radhakrishnan, Jerry L. Hunter, Yongho Sohn, Kevin R. Coffey, Graeme E. Murch, and Irina V. Belova

Erratum to: J Phase Equilib Diffus

DOI 10.1007/s11669-014-0344-4

$$
L_{i i}=\frac{c_{i} D_{i}^{*}}{k T}=c_{i} M_{i} \quad \text { if } \quad L_{i j}=0
$$

Due to a typesetting error, Eq (4) is incorrect. The equation should appear as follows:

The online version of the original article can be found under doi: 10.1007/s11669-014-0344-4.

Nagraj S. Kulkarni, Knoxville, TN, USA; Robert J. Bruce Warmack and Bala Radhakrishnan, Oak Ridge National Laboratory, Oak Ridge, TN, USA; Jerry L. Hunter, Virginia Polytechnic Institute and State University, Blacksburg, VA, USA; Yongho Sohn and Kevin R. Coffey, University of Central Florida, Orlando, FL, USA; Graeme E. Murch and Irina V. Belova, The University of Newcastle, Callaghan, NSW, Australia. Contact e-mail: Nagraj@alumni.ufl.edu. 